\title{
Research on Construction Monitoring of Large-Span Steel Pipe Truss Structure
}

\author{
Kongliang Chen ${ }^{1 *}$, Guoqing Yuan1, Liankun Wang1, Wenzhi Zhang1, Xiaoke Wang² \\ ${ }^{1}$ Wuyi University, Jiangmen, China \\ ${ }^{2}$ Shanghai Baoye Group Corp., Ltd, Shanghai, China \\ Email: *kongliangchen@126.com
}

How to cite this paper: Chen, K.L., Yuan, G.Q., Wang, L.K., Zhang, W.Z. and Wang, X.K. (2019) Research on Construction Monitoring of Large-Span Steel Pipe Truss Structure. Open Journal of Civil Engineering, 9, 255-267.

https://doi.org/10.4236/ojce.2019.94018

Received: August 28, 2019

Accepted: October 14, 2019

Published: October 17, 2019

Copyright (c) 2019 by author(s) and Scientific Research Publishing Inc. This work is licensed under the Creative Commons Attribution International License (CC BY 4.0).

http://creativecommons.org/licenses/by/4.0/

\begin{abstract}
The steel roof of Jiangmen gymnasium is the large-span spatial pipe truss structure, which is composed of main truss, secondary truss and stable truss. This paper systematically expounds the construction simulation analysis, the composition of the construction monitoring system, the monitoring method, and the arrangement of measuring points. The construction simulation analysis simulates the whole process of the main truss cumulative lifting installation, the secondary truss and auxiliary structure hoisting, and then the main truss for overall unloading, which is the difficulty of the whole project. The results of the structural construction monitoring show that the roof structure is in a safe state, and the fine construction simulation analysis provides a theoretical basis for the construction process, and the theoretical value of the simulation analysis is in good agreement with the measured data. In addition, vertical displacement and stress are obvious mutations in the unloading stage of roof support, but the stress of each measuring point is in elastic working condition, which meets the design requirements, indicating the correctness of the model and method in construction simulation analysis and calculation, and also provides reference for the design and construction of related projects in the future.
\end{abstract}

\section{Keywords}

Gymnasium, Pipe Truss, Monitoring, Stress, Displacement

\section{Introduction}

At present, the large-span spatial steel pipe truss structure is widely used in various large-scale stadiums, theaters, convention and exhibition centers and other important landmarks. It is the embodiment of modern civilization with new materials, new technologies and new techniques as comprehensive technology 
[1] [2]. However, the steel structure of large stadiums has a large span and complicated forces [3] [4]. In order to ensure the safety, applicability and durability of the structure, it is necessary for major engineering structures to carry out structural monitoring during the construction phase [5] [6] to ensure the structure with no quality defects. The whole process of construction of the gymnasium steel roof was simulated and analyzed, and the stress and deformation monitoring were carried out. And the results show that the simulation analysis is in good agreement with the measured data in these papers [7] [8], which verifies the correctness of the simulation analysis.

Therefore, real-time monitoring of such large-scale projects and the establishment of sound monitoring system are of great significance for analyzing the structural stress state and ensuring structural safety [9] [10] [11] [12] [13]. The structure of the construction monitoring system, construction monitoring method and measuring point layout with a gymnasium as the project background are introduced in this paper. The whole process stress and deformation monitoring during the construction stage are carried out to ensure the safety of the structure, and an assessment for the safety of the structure during the construction stage will be provided for operation management. The indicators also provide reference for the design and construction of related projects in the future.

\section{Project Overview}

The effect picture of Jiangmen Gymnasium is shown in Figure 1. The steel roof structure consists of main truss, secondary truss, stable truss, support, tie rod and peripheral roof are shown in Figure 2. The main truss consists of two rectangular trusses that intersect in the north-south direction and the east-west direction. The cross-section of the upper and lower chords of the main truss is mainly $\Phi 760 \times 16$ and $\Phi 560 \times 16$, and the cross-section of the web is mainly $\Phi 245 \times 12$ and $\Phi 402 \times 16$. The stable truss, support and tie rods are arranged in the vertical direction of the secondary truss. The secondary truss is a supporting skeleton for the shape of the stadium roof, which is an east-west plane truss. One end is supported on the surrounding concrete column and the other end is connected to the main truss. The cross-section of the upper and lower chords of the secondary truss is mainly $\Phi 245 \times 8$ and $\Phi 299 \times 12$, and the main section of the rib is mainly $\Phi 133 \times 5$. The stable truss support and tie rod members are mainly steel tubes.

\section{Construction Technology of the Gymnasium}

\subsection{Installation and Unloading Plan of Gymnasium Roof}

The construction of the gymnasium roof is based on the principle of completing the main tasks first and then completing the secondary tasks. The whole construction stage can be divided into 17 stages, in which the installation sequence is main truss $\rightarrow$ secondary truss $\rightarrow$ stable truss, support, tie rod $\rightarrow$ peripheral roof, and the main truss and the secondary truss will be constructed in 1 to 11 


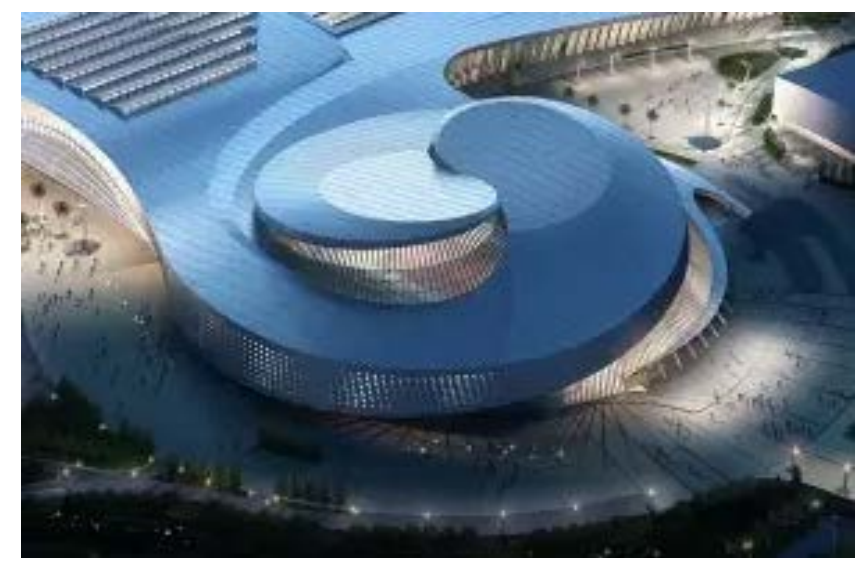

Figure 1. Effect picture of stadium.

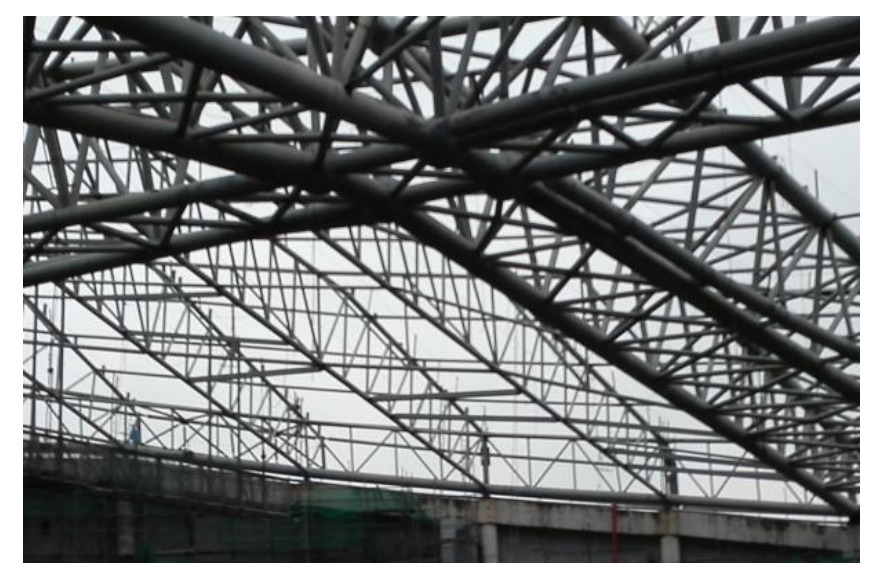

Figure 2. Steel roof of gymnasium.

stages, 12 stage will be unloaded and removed the tire frame, and the gantry crane will be unloaded and removal in stage 12, and stable truss and other poles will be installed in 13 to 17 stages. The lifting installation of the main truss structure is shown in Figure 3 and Figure 4, and the hoisting construction of the secondary truss is shown in Figure 5, and the gantry crane unloading is shown in Figure 6.

The steel roof of the gymnasium needs to be unloaded as a whole, and the tonnage of the main truss is about $1200 \mathrm{t}$. In order to ensure the safety and overall shape of the structure, it is necessary to control the synchronous decline of each point, in order to ensure that the entire unloading process is implemented according to the plan, and it is combined with the theoretical calculation of the unloading data, and the theoretical unloading result of overall structure and may be different from those of the actual structure. Therefore, the overall unloading theoretically must be calculated accurately to ensure the safety of the unloading conditions.

\subsection{Construction Simulation Analysis}

The material of steel structure is Q345B, and the concrete material is C40. The 


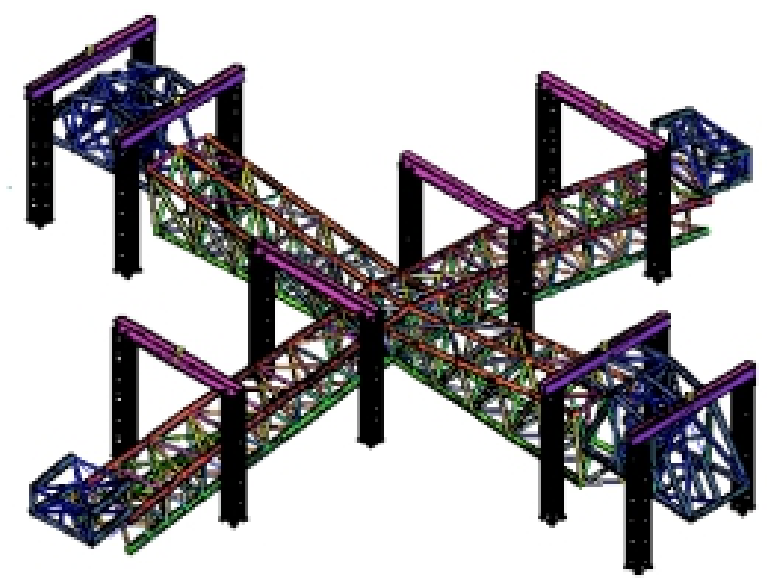

Figure 3. Schematic diagram of main truss lifting.

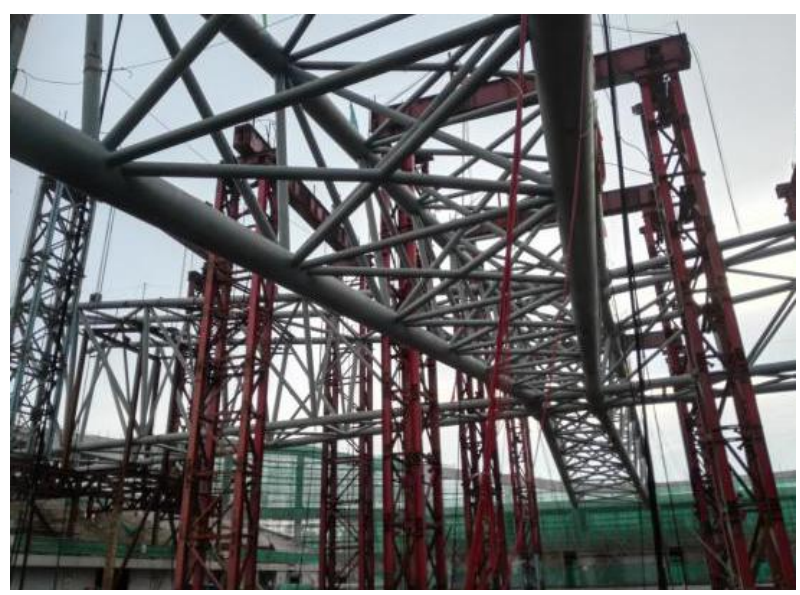

Figure 4. Main truss lifting.

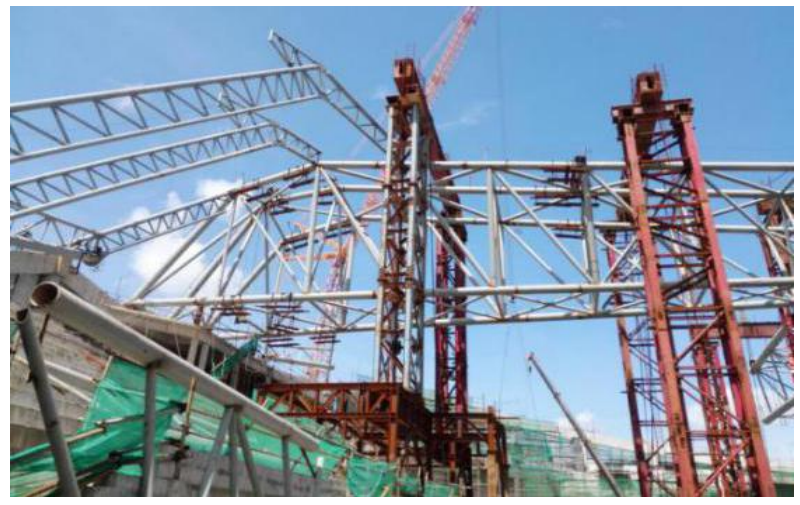

Figure 5. Secondary truss hoisting construction.

simulation calculation of this project is calculated by Midas finite element program. According to the parameters of the design drawing, the round steel pipes of $\Phi 760 \times 16, \Phi 560 \times 16, \Phi 245 \times 12-\Phi 402 \times 16$ cross section are simulated by beam element, and the concrete column and beam are simplified into beam elements, and the support is simplified as a hinge. The finite element model of the 


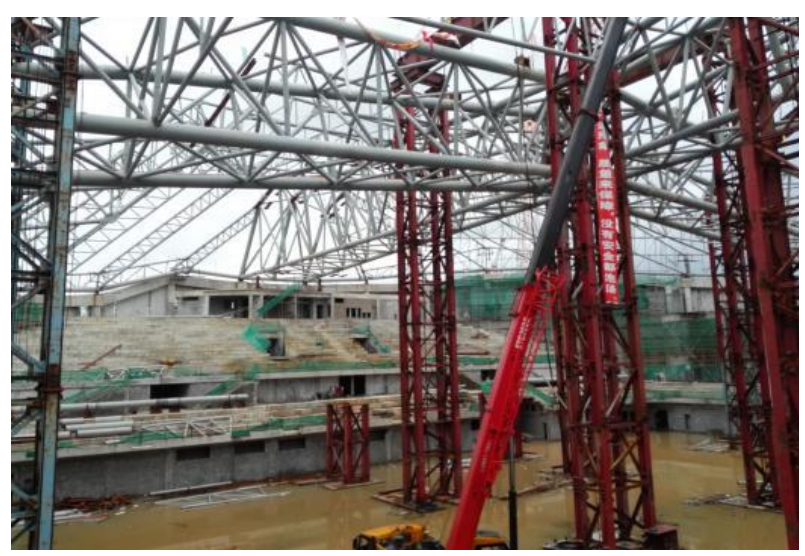

Figure 6. Remove the tire frame after unloading.

gymnasium is shown in Figure 7, which has a total of 10,653 units with a total of 110 sections, and steel roof model of the gymnasium is shown in Figure 8.

According to the construction characteristics of the roof structure and the requirements of construction monitoring and analysis, the method adopted is the step-by-step calculation method, and the simulation calculation of the construction process is carried out by using MIDAS. The so-called dressing calculation refers to gradually increasing the structural unit and changing the construction load according to the predetermined construction sequence and process flow, calculating the stress on the deformation, internal force and dangerous section of the structure at each construction stage, and obtaining the internal force state of the whole construction process.

Figure 9 to Figure 10 are respectively the stress cloud diagram and the vertical displacement cloud diagram in the unloading stage. The calculation results show that the maximum unloading stress is $196.8 \mathrm{MPa}$, which is at the lifting point of the upper main truss, and the stress value of most rods is between 30 $\mathrm{MPa}$ and $70 \mathrm{MPa}$, and the maximum vertical displacement is $13.9 \mathrm{~cm}$, and the theoretical calculation result shows that there is a significant mutation at this stage.

\subsection{Construction Monitoring System}

Construction monitoring includes strain monitoring and displacement monitoring. The strain monitoring system of the project is mainly composed of strain sensor subsystem, data acquisition and transmission subsystem, data management and analysis subsystem, which can realize continuous collection, automatic storage and real-time continuous monitoring of monitoring data. According to the monitoring content, the sensor subsystem lays up a strain sensor in the key parts of the gymnasium structure to obtain the response information of the structure under the load. The data acquisition and transmission subsystem collects the information transmitted by the sensor, and modulates and processes the analog signal. Convert to a digital signal and transfer the signal to the data management and analysis subsystem, as shown in Figure 11. 


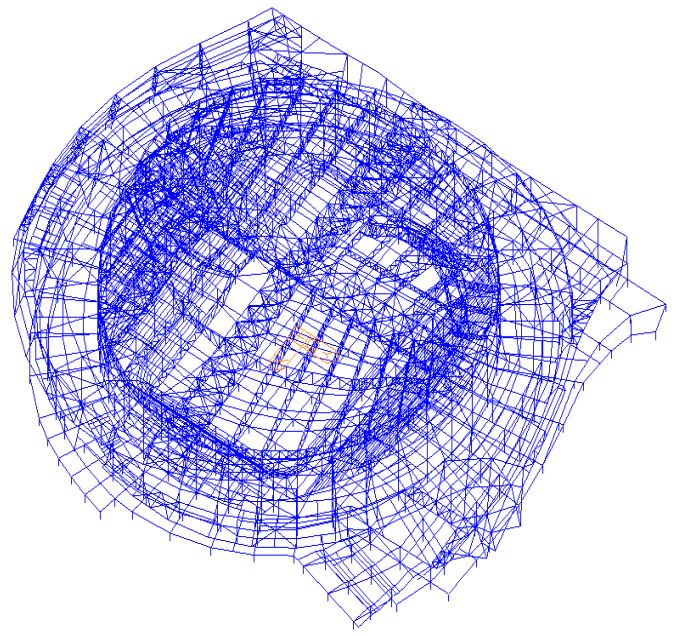

Figure 7. Overall model of the gymnasium.

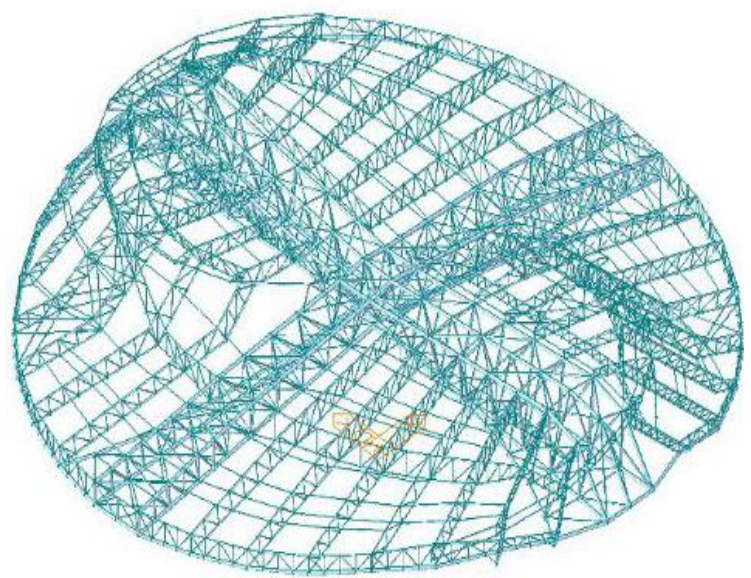

Figure 8. Steel roof model of the gymnasium.
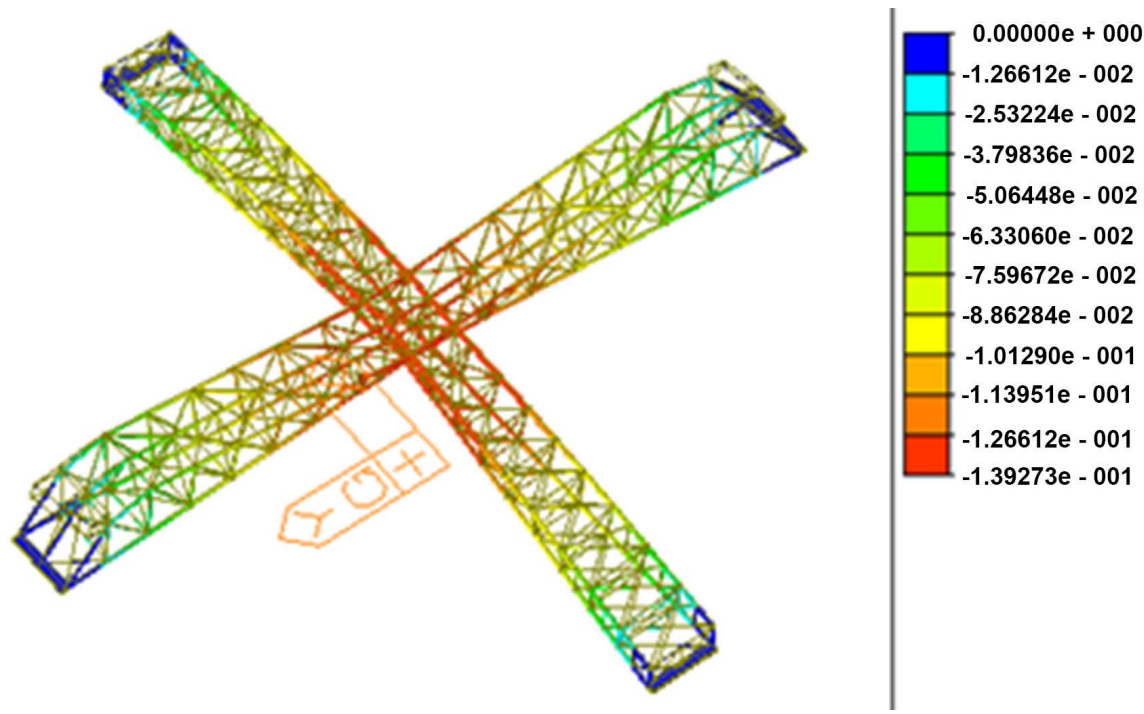

Figure 9. Deformation of the main truss during the unloading stage (Unit: $\mathrm{m}$ ). 

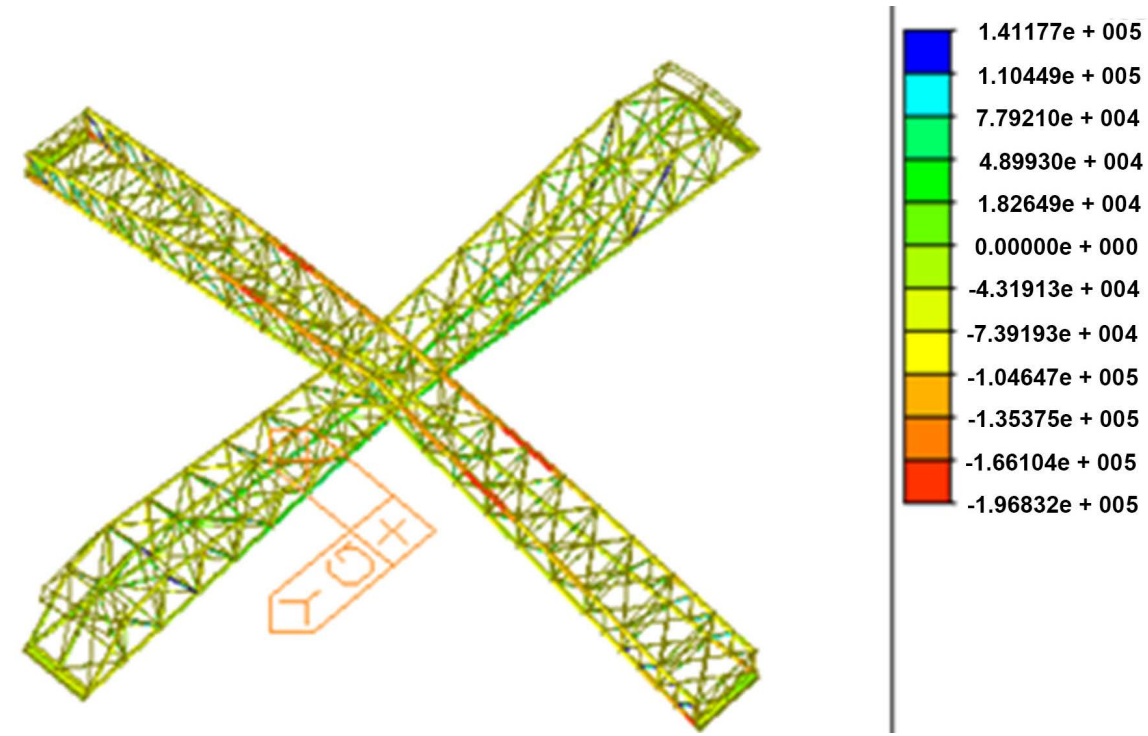

Figure 10. Main truss stress during unloading stage (Unit: $\mathrm{Pa}$ ).

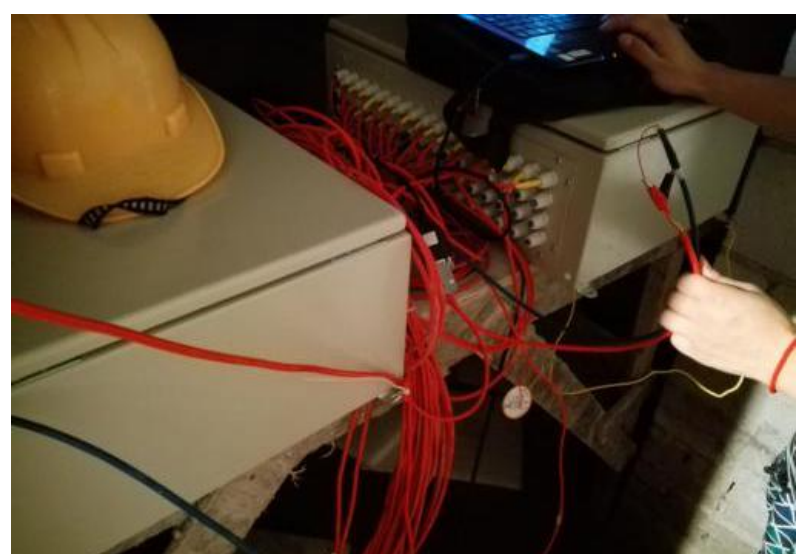

Figure 11. Strain acquisition system.

This project adopts vibrating wire strain system, and arranges vibrating wire strain sensors in key parts of the structure. As shown in Figure 12, 1 to 6 sections are arranged on the main truss, and each section has 8 strain sensors. The strain sensor wires are processed into two bundles as shown Figure 13, so that there is no wire chaos or wire tie or even wire breakage during the main truss jacking process, ensuring the accuracy of data acquisition.

The stadium uses high-precision total station to measure in the deformation monitoring. The position of the deformation observation point is shown in Figure 14, and monitoring site photos are shown in Figure 15. It is divided into 28 measuring points in four measuring areas of $\mathrm{A}, \mathrm{B}, \mathrm{C}$ and $\mathrm{D}$. The observation data for each measurement point contains displacement data in three directions. In theoretical analysis, the vertical displacement of the unloading stage has a large mutation, while the lateral displacement is disordered and the data changes are stable. Therefore, the vertical deformation is the focus of monitoring. 

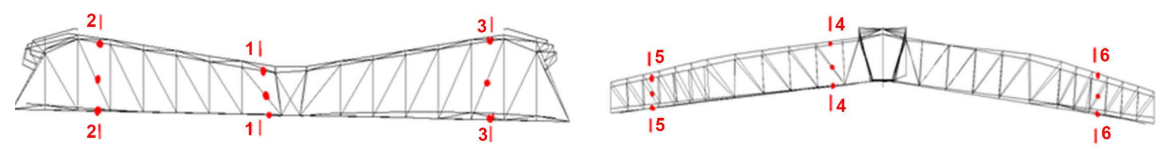

Figure 12. The arrangement of stress point.

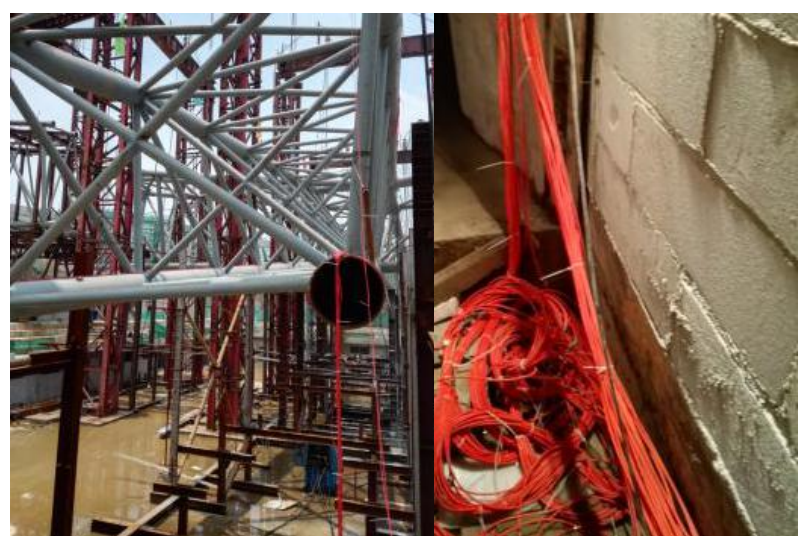

Figure 13. Strain sensor wire.

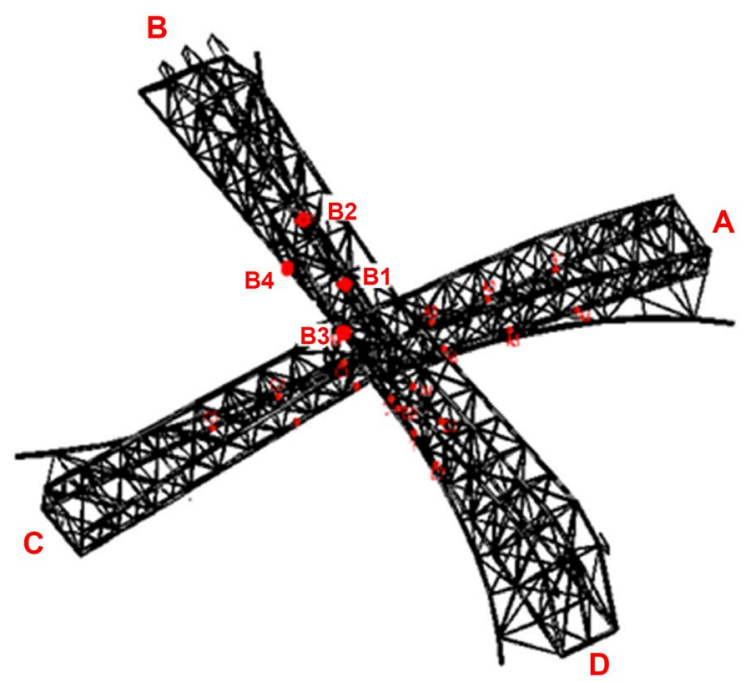

Figure 14. The displacement point of main truss.

\section{Analysis of Construction Monitoring Results}

The steel roof structure is transformed from the lifting of the main truss, the installation of the secondary truss to the demolition of temporary support, and the conversion of the load from the temporary supporting tower to the steel structure itself is completed. This is a process in which the permanent structure is gradually transferred and the internal force is redistributed. Due to the large number of monitoring points and limited to the length of the article, this paper only selects some stress measurement points and displacement measurement points of the main truss of the stadium to analyze and find out the corresponding change rules. 


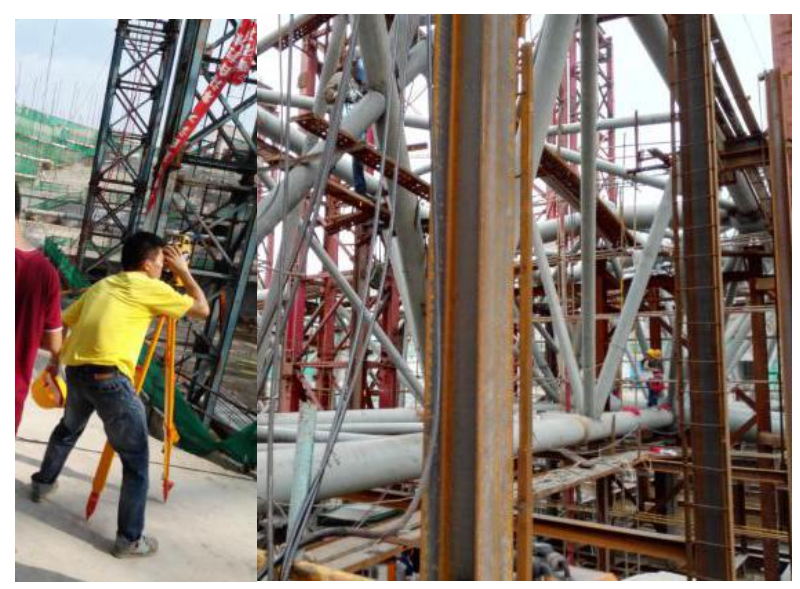

Figure 15. Monitoring site photos.

It can be seen from Figure 16 to Figure 17 that there are three stress measuring points of the chord, which are the lower chord of No.1 section, the upper chord stress curves of No.2 and No.6, and the stress curve of the measuring point does not change significantly before unloading, and the stress change is in the range of $-10 \mathrm{MPa}$ to $10 \mathrm{MPa}$, and the internal force variation of the chord measuring points of the three sections is basically similar. During the unloading of the 12 stage tire frame, the stress value suddenly increased sharply, and the increased stress value is about $40 \mathrm{MPa}$ to $60 \mathrm{MPa}$. The law of stress change on web member is similar to that of the chord. Under the unloading condition, the stress of the web member is suddenly increased. The measuring points have the same variation law and stress abrupt value, but far less than the yield strength of the steel $(345 \mathrm{MPa})$. After the stage of unloading, the internal force of the rod gradually shifts and the internal force redistribution occurs. The law of stress change is greatly affected by factors such as time and weather, and the stress of the bars is increased or decreased, but the overall change is little.

It can be concluded from Figure 18 to Figure 19 that the lateral deformation in the $\mathrm{Y}$ direction changes disorderly with the development of the construction stage. Even in the unloading stage, there is no obvious law in the $\mathrm{Y}$ direction displacement, and the $\mathrm{X}$ direction displacement variation law is similar to the $\mathrm{Y}$ direction. From the vertical deformation diagram, it can be seen that in the unloading stage, there is a large abrupt change in the vertical deformation, and the maximum value of the vertical deformation is $13.2 \mathrm{~cm}$, while the vertical deformation in other construction stages is small, which shows that the main truss bears a large load during the unloading stage. The vertical displacement abrupt stage of the main truss coincides with stress abrupt stage of the main truss, and the vertical deformation of the structure, and the vertical deformation of the structure after unloading changes little.

The stress values of the lower chord unloading stage of section 1 to section 3 are shown in Table 1, and these sections have two lower chords, which are represented respectively by LC1 and LC2. Two strain sensors are arranged for 
Chord stress

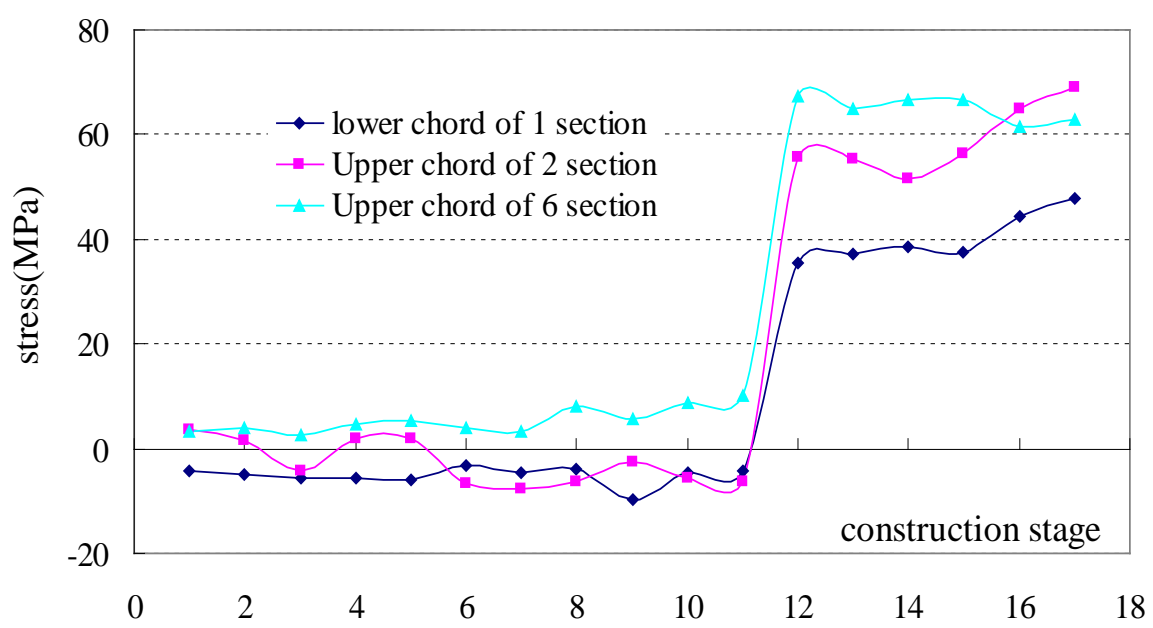

Figure 16. Chord stress.

web member stress

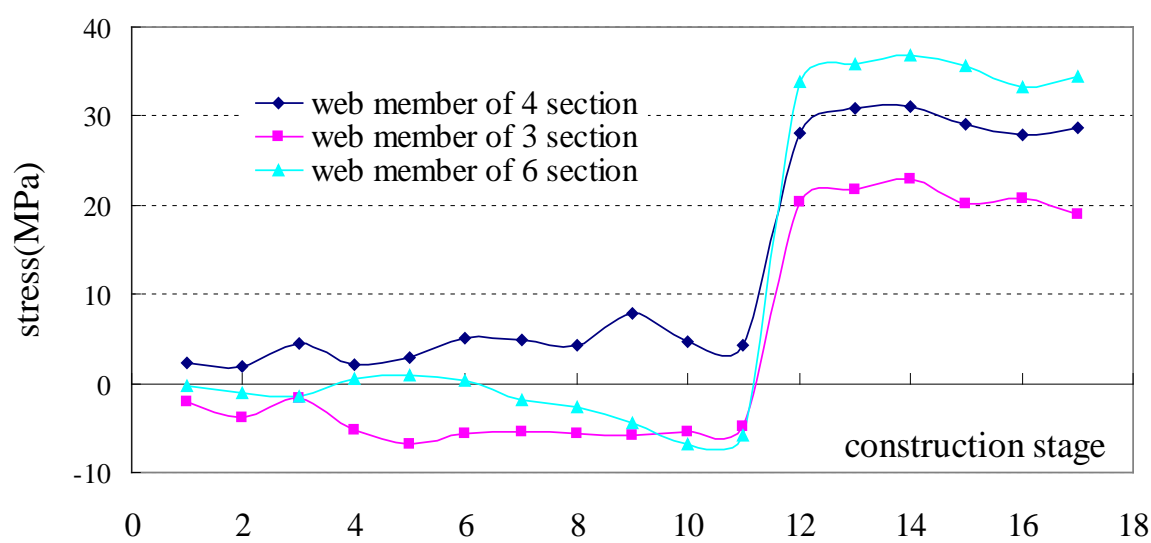

Figure 17. Web member stress.

Lateral Displacement

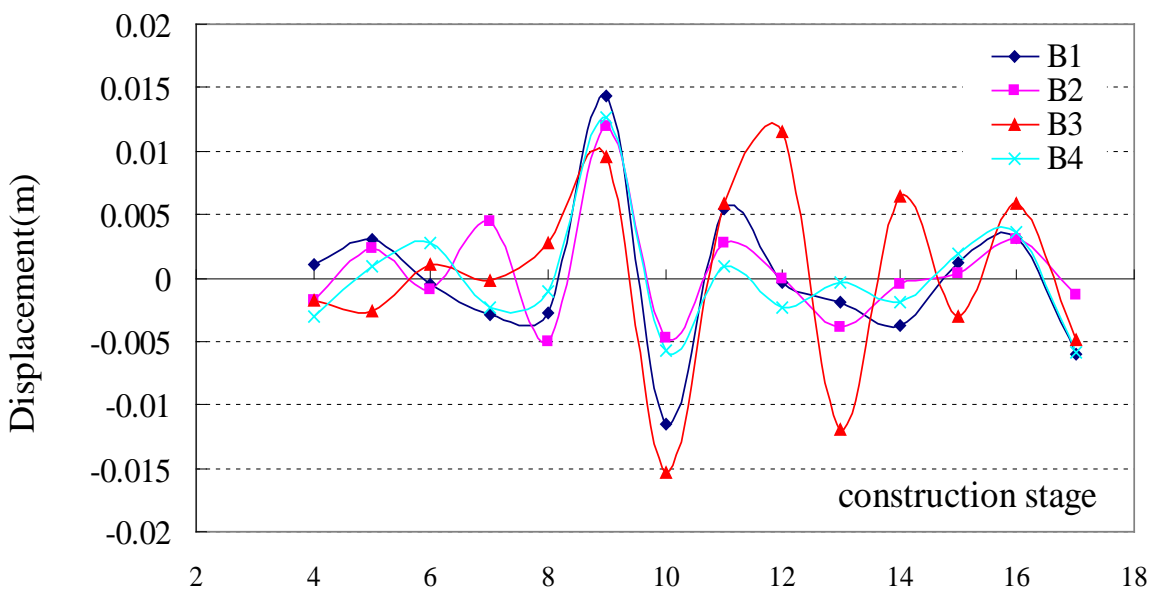

Figure 18. Lateral displacement. 


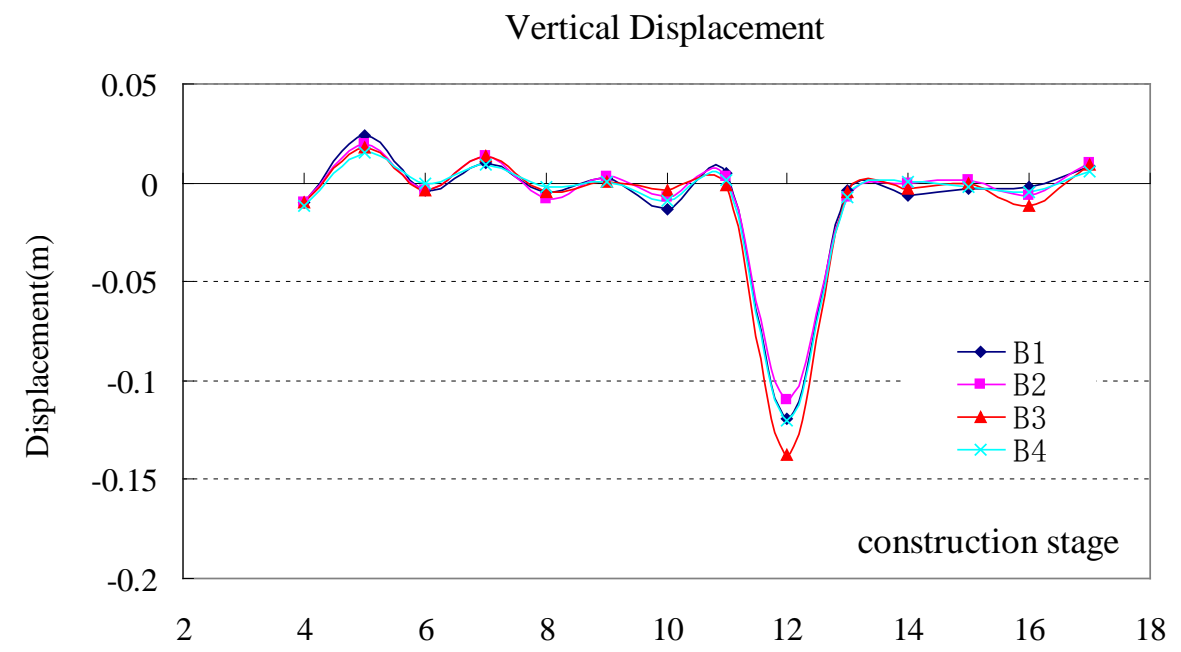

Figure 19. Vertical displacement.

Table 1. Comparison of stress values during unloading.

\begin{tabular}{|c|c|c|c|c|c|c|}
\hline \multirow{3}{*}{$\begin{array}{c}\text { Serial } \\
\text { number }\end{array}$} & \multirow{3}{*}{ position } & \multicolumn{2}{|c|}{ Construction stress } & \multirow{2}{*}{$\begin{array}{l}\text { Change in } \\
\text { stress } \\
\text { (2)-1) }\end{array}$} & \multirow{2}{*}{$\begin{array}{c}\text { Theoretical } \\
\text { value of stress } \\
\text { Stage } 12 \\
\text { (3) }\end{array}$} & \multirow{3}{*}{$\begin{array}{l}\text { Stress measured } \\
\text { value and } \\
\text { rationality } \\
\text { Value comparison } \\
\text { (2) / (3) }\end{array}$} \\
\hline & & $\begin{array}{l}\text { Stage } 11 \\
\text { (1) }\end{array}$ & $\begin{array}{l}\text { Stage } 12 \\
\text { (2) }\end{array}$ & & & \\
\hline & & $\mathrm{MPa}$ & $\mathrm{MPa}$ & $\mathrm{MPa}$ & $\mathrm{MPa}$ & \\
\hline \multirow{4}{*}{ Section 1} & LC1 & -4.4 & 35.64 & 40.04 & 48 & 0.74 \\
\hline & LC1 & -10.66 & 37.2 & 47.86 & 48 & 0.78 \\
\hline & LC2 & -17.6 & 46.14 & 63.74 & 48 & 0.96 \\
\hline & LC2 & -7.24 & 48.08 & 55.32 & 48 & 1.00 \\
\hline \multirow{4}{*}{ Section 2} & LC1 & -9.06 & 16.6 & 25.66 & 55 & 0.30 \\
\hline & $\mathrm{LC} 1$ & -12.76 & 29.1 & 41.86 & 55 & 0.53 \\
\hline & LC2 & -6.3 & 55.82 & 62.12 & 55 & 1.01 \\
\hline & LC2 & -12.6 & 44.34 & 56.94 & 55 & 0.81 \\
\hline \multirow{4}{*}{ Section 3} & LC1 & --15 & 47.26 & 62.26 & 55 & 0.86 \\
\hline & LC1 & -5.02 & 50.8 & 55.82 & 55 & 0.92 \\
\hline & LC2 & -8.94 & 46.64 & 55.58 & 55 & 0.85 \\
\hline & LC2 & 10.9 & 60.72 & 49.82 & 55 & 1.10 \\
\hline
\end{tabular}

each lower chord, and the arrangement of the sensors is symmetrical about the axis of the rod. As shown in Table 1, the stress values in the unloading stage have large mutations, and the variation value is generally about 40 to $60 \mathrm{MPa}$, but the variation value of some strain sensors is less than $30 \mathrm{MPa}$. There is also an error in the value of the measured stress at the same position of the same rod, but the error is on the whole within $10 \mathrm{MPa}$. Moreover, the ratio of the measured stress value of most rods to the theoretical value is about 0.7 to 1.1 , and the ratio is between a reasonable range, but there are also some points where the ratio is not in this range because of temperature or environmental impact. 
From the measured stress and displacement results of each measuring point, the measured results are basically consistent with the theoretical results, which fully demonstrates the correctness of theoretical analysis.

\section{Conclusions}

In this paper, the stress and displacement monitoring system is used to monitor the stress and displacement of key members in the construction stage of Jiangmen gymnasium, and the following conclusions are drawn.

1) Through real-time monitoring of the whole process of the stadium construction stage, the results show that the maximum stress of the steel structural members is within the reasonable design range, and the stress in the unloading stage is obviously abrupt, but the internal force of the rod is much smaller than the yield strength of the material. The stress state of the point is always in the elastic working state, and the entire structure is safe to meet the design requirements.

2) The lateral displacement of the measuring points in each construction stage changes disorderly. The vertical displacement of the measuring points is basically the same. Before the unloading stage and after the unloading stage, the vertical displacement changes are relatively stable, and the vertical displacement of the unloading stage is about obvious mutation, which is basically consistent with the actual calculated value, indicating that the structural stiffness meets the design requirements.

3) Through the analysis results of monitoring the steel structure construction in the gymnasium, the selection of the monitoring system of this project is reasonable, and the selection of key points and key parts is effective, which is of great significance for analyzing the structural stress state and ensuring the structural construction safety. The monitoring methods, measuring point arrangements and methods in this paper can provide reference for similar engineering structures.

\section{Acknowledgements}

The paper is supported by the Special Funds of the National Natural Science Foundation of China (11502172) and Guangdong Science and Technology Department Project (2016A040403125).

\section{Conflicts of Interest}

The authors declare no conflicts of interest regarding the publication of this paper.

\section{References}

[1] Dong, S.L., Xing, D. and Zhao, Y. (2012) Application and Development of Modern Long-Span Space Structures in China. Spatial Structures, 18, 3-16.

[2] Dong, S.L. (2010) Development and Expectation of Spatial Structures in China. 
Journal of Building Structures, 31, 38-51.

[3] Lin, B., Cao, W., Dong, J.Y., Pei, S.Y. and Liang, S.Y. (2015) Installation Technology for Multi-Story Overweight and Long-Span Steel Truss of Hanzhou Internation Expo Center. Steel Construction, 30, 69-93.

[4] Xie, H.P., Jin, Z.C. and Luo, Z.L. (2017) Consturction of Large-Span Inclined Arch Pipe Truss Installation. Construction Technology, 46, 33-35.

[5] Liu, X.W., Guo, Y.L. and Guo, Y.F. (2010) Application of Jack Element Model for Numerical Simulation of Removing Temporary Supports of Large-span Steel Roof. Construction Technology, 39, 24-28, 33.

[6] Zong, Z.H., Wang, T.L., Huang, D. Z. and Zheng, Z.F. (2002) State-of-the-Art Report of Bridge Health Monitoring. Journal of Fuzhou University (Natural Science), 30, 127-153.

[7] Wang, X.L., Rong, Z.H., Yang, B.X., Luo, C.D., Zhou, Y. and Wu, X.Y. (2017) Whole Process Simulation Analysis and Health Monitoring of Spatial Pipe Truss Structure Gymnasinm. Journal of Architecture and Civil engineering, 34, 18-25.

[8] Qian, J.R. Zhang, W.J., Zhao, Z.Z., Pan, P., Zhong, C.L. and Jiang, Q.Z. (2009) Simulation and Monitoring for the Construction of the Steel Roof of the Peking University Gymnasium. China Civil Engineer Journal, 42, 13-20.

[9] Patrikar, A. and Pathak, K. (2016) Fully Stressed Design of Fink Truss Using STAAD. Pro Software. Open Journal of Civil Engineering, 6, 631-642. https://doi.org/10.4236/ojce.2016.64051

[10] Mesda, Y. (2013) Analytical Study of the Cable-Truss Systems on the Glass Certain Walls with Vertical Uses. Engineering, 5, 819-826.

https://doi.org/10.4236/eng.2013.510099

[11] N YQ, Jian, S.F. and Ko, J.M. (2001) Application of Adaptive Probabilistic Neural Network to Damage Detection of Tsing Ma Bridge. Health Monitoring and Management of Civil Infrastrutures Systems, SPIE, USA, Vol. 4337, 347-356. https://doi.org/10.1117/12.435610

[12] Farrar, C.R., Duffey, T.A., Doebling, S.W., et al. (1999) A Statistical Pattern Recognition Paradigm for Vibration-Based Structural Health Monitoring. The 2 nd International Workshop on Structural Health Monitoring, Stanford, CA, 245-257

[13] Zhou, G.G., Chen, X., Wang, Y.M., et al. (2010). Key Construction Technology for the Steel Truss with Large Cantilever on the Stadium of Nanchang International Sports Center. Construction Technology, 39, 78-81. 